\title{
O exercício do direito fundamental de manifestação: a ingerência pelas forças de segurança ${ }^{1}$
}

\author{
The exercise of the manifestation fundamental right: \\ interference by security forces
}

\author{
MANUEL MONTEIRO GUEDES VALENTE ${ }^{2}$ \\ manuelmonteirovalente@gmail.com \\ GALILEU - REVISTA DE DIREITO E ECONOMIA - e-ISSN 2184-1845 \\ Volume XXI $\cdot 1^{\text {st }}$ January Janeiro $-30^{\text {TH }}$ June Junho $2020 \cdot$ pp. 172-178 \\ DOI: http://doi.org/10.26619/2184-1845.XXI.1.8 \\ Submitted on October $6^{\text {th }}, 2019 \cdot$ Accepted on June $4^{\text {th }}, 2020$ \\ Submetido em 6 de outubro, 2020 . Aceite a 4 de junho, 2020
}

Iniciamos este debate por cumprimentar os membros do júri destas provas públicas de doutoramento em Direito da nossa Universidade: Magnífico Reitor, Doutor José Amado da Silva, sendo uma honra estar num júri presidido pela mais alta instância académica e científica desta academia, Doutora Paula Veiga, Professora da Faculdade de Direito da Universidade de Coimbra, à qual dirigimos um cumprimento especial por também a considerar nossa casa científica, Doutor Nuno Poiares, Professor do Instituto Superior de Ciências Policiais e Segurança Interna, instituição que cumprimento de modo especial por ser a nossa casa mãe, e Doutor André Ventura, Professor da Universidade Autónoma de Lisboa e Orientador desta tese de doutoramento.

Um cumprimento especial à família e à plateia, aqui presentes, como legitimando o ato público e solene, ao qual almejaram associar-se dignificando-o e prestigiando a candidata, Mestre Ana Maria dos Santos Robalo, que cumprimentamos e fazemos votos de que estas provas decorram com elevação, grandiosidade e sejam um momento de felicidade académica e científica. A nossa arguição assenta em três partes - análise global, análise formal e

\footnotetext{
1 Arguição da tese de doutoramento da Mestre Ana Maria dos Santos Batista Robalo, apresentada a provas públicas na Universidade Autónoma de Lisboa, no dia 10 de julho de 2019.

Scientific discussion of the PhD thesis of Master Ana Maria dos Santos Batista Robalo, presented to public tests at the Autonomous University of Lisbon, on July 10, 2019.

2 Doutor em Direito pela Universidade Católica Portuguesa. Professor Associado da Universidade Autónoma de Lisboa. Presidente do Instituto de Cooperação Jurídica Internacional. Professor do Programa de Mestrado e Doutoramento em Ciências Criminais da PUC-RS e Professor Convidado da ESP/ANP - Polícia Federal - Brasil. Advogado e Jurisconsulto.
} 
análise material - devendo ver nas nossas críticas motivo de aprofundamento e de espaço de debate científico para um melhor olhar sobre o tema em questão.

\section{Primeiro momento - Análise Global}

Tema sempre atual, pertinente e que suscita curiosidade científico-jurídica tendo em conta a data do regime jurídico - 1974 - e a sequente Constituição da República Portuguesa (CRP) que é de 1976.

Poder-se-ão levantar questões de inconstitucionalidade superveniente, como o faz a candidata, mas também poder-se-á considerar que uma interpretação normativa conforme a CRP76 afastará essas questões jurídicas. É se salientar que o legislador, não obstante vários estudos desenvolvidos sobre a temática - como os que o ICPOL promoveu nos anos 2005 a 2008, cuja publicação dos mesmos a candidata procede -, ainda não se prendeu com esta questão ou com a necessidade de proceder a uma alteração ou a aprovação de um novo regime.

Esta preocupação está patente no seu trabalho, mas parece-nos que se prende muito á questão da responsabilização dos atos desviantes - administrativos, civis e criminais - do que com a novas nuances e formas de manifestações e reuniões próprias da era digital. Veja-se que as suas conclusões (pp. 298 e ss.) têm um foco excessivo na questão da responsabilização, talvez por existir em si uma tendência positivista que a possa conduzir a um estado de normativização da vida e do exercício de direitos ou talvez seja a sua veia mais de polícia a tentar dar um cunho operativo e sancionador às violações normativas ou ao desrespeito por bens e valores jurídicos de uma sociedade constitucional democrática. Voltaremos a este tema em breve.

Coloca questões que à partida são de resposta simples se olharmos para o quadro jurídico, mas se questionarmos as próprias questões de partida, a resposta não será fácil, desde logo porque não nos explica que dimensão de legitimidade está presente na segunda pergunta (pp. 21, 22 e 298): se jus normativo-constitucional ou se apenas sociológica ou se ambas?

Em termos gerais e na linha da Professora Paula Veiga, e apesar de ter optado por um estudo de um regime, com pouca crítica assertiva político-constitucional e criminal, mesmo que possa dizer que estudou o modelo do Reino de Espanha, mas sem apresentar em concreto uma visão que avocasse a unidade do sistema considerado nos seu todo - constitucional-administrativo-criminal-civil -, consideramos que, e para a descansarmos, deve ser aprovada nestas provas de doutoramento, por a nossa apreciação ser globalmente positiva. 


\section{Segundo momento - Análise formal}

No que respeita às questões de forma, temos alguns apontamentos a fazer. Quanto à divisão e sistematização da tese, consideramos que devia ter algum cuidado, uma vez que a sua tese tem 3 partes em 348pp., sendo que a parte 1 tem apenas 21pp., ao passo que a parte 2 tem 167pp. e parte 3 tem 84pp.; e apresenta-nos uma conclusão com 27pp.

Veja que a parte 1 tem apenas um capítulo com as ditas 21pp., conquanto a parte 2 tem 5 capítulos - I, 13pp, II 9pp., III 46pp., IV 31pp., e o V 66pp. - e a parte 3 tem 3 capítulos I 33pp., II 35pp. e o III 16pp.. Existe uma assimetria quer quanto às partes quer quanto aos capítulos. É algo que no futuro tem de corrigir.

Veja que há matérias e questões/afirmações - v. g., «falta norma de responsabilização» (pp. 299 e ss), «falta uma norma que tipifique claramente...» (p. 306 e ss.) - que se prendem com a sua primeira questão de partida, e que recolocou nas conclusões que deviam ter sido tratadas antes, p. e., no último capítulo da parte 3 , obedecendo assim ao princípio da ultima ratio do Direito sancionatório - penal e administrativo sancionador. As conclusões - 21pp. deviam ter sido mais concisas e não expositivas, caindo na armadilha de voltar a repristinar o teor da Ley Orgânica 4/2015 de Espanha.

Quanto ao discurso escrito, que é percetível e compreensível, nota-se, em vários momentos,

(i) o abandono do discurso jurídico para um discurso mais policial ou sociológico «escolha de um bom local» (p. 85) -;

(ii) outras vezes faltam vírgulas ou estão colocadas no lugar errado (p. 300), assim como algumas falhas de concordância (p. 145) -;

(iii) como utiliza conectores de forma menos correta no plano semântico - p. e., «todavia» (24vezes), quando na maior parte das vezes o sentido do discurso é «contudo» e «mas», uma vez que não está num discurso contraditório, mas adversativo,

(iv) trata alguns autores por Professor, outros por Prof. - pp. 69, 121 (n. 223), 206, 208 -, e outros apenas pelo nome, quando devia tratar todos os autores pelo nome científico por que são conhecidos,

(v) e, até mesmo, trata o mesmo autor de várias formas: p. e., José Joaquim Gomes Canotilho (pp. 30 e 31) ora Gomes Canotilho (pp. 32, 69) e Canotilho (pp. 44, 78),

(vi) o modo de citar é o de nota de rodapé, mas ao longo do texto temos situações de citação de autor/data - pp- 78, 98 e 213 -, como coloca idem, quando devia colocar ibidem, e ainda umas vezes coloca a indicação da nota de rodapé dentro do período frásico e outras fora do período frásico - a título de exemplo vejam-se as pp. 118, 119, 120, assim como a indicação do numerário das coimas é diferenciado; 
(vii) em suma, precisa de uma revisão para lhe dar maior consistência sistemático-científica.

No que respeita à bibliografia/referências bibliográficas, apresenta 24pp. com entradas doutrinárias e documentais, sendo que, mesmo havendo alguma diversificação e autores estrangeiros, há a falta de autores como Otto Bachof, Rolf Stober, Bernhard Schlink, cujos textos referentes aos direitos fundamentais, à atividade de polícia e à restrição daqueles, estão traduzidos pela Gulbenkian e a Editora da Lusíada; assim como exigia-se que tivesse tido em conta obras e estudos que utilizou atualizadas e que ateriam ajudado a compreender melhor a ideia de domínio público e domínio privado dos espaços, cujo tema lhe falaremos de seguida.

No que respeita ao modelo de investigação da sua tese, que nos apresenta a pp. 23 «investigação doutrinal, comparativos e o histórico» -, consideramos que não o respeitou de todo, pois foi mais uma análise do regime vigente seguindo descritivamente a posição de autores no que respeita à restrição de direitos e liberdades fundamentais sociais.

\section{Terceiro momento - Análise material}

No plano material, sendo que, como dissemos, o tema que nos traz é de extrema relevância jurídica, poder-se-ia dizer que muitas questões haveria para convocar e aqui debulhar, mas o tempo é ditador e seremos diretos e trataremos dos pontos mais cruciais e prementes que a sua tese nos suscitou.

1. Iniciaremos com as questões de partida e que refletem a espinha dorsal da sua tese, que apresenta a páginas 21 a 22 e depois regressa nas conclusões, pp. 298 e ss.

Quanto à primeira questão, parece-nos que falta a sua situalização temporal, porque a resposta tanto pode ser sim ou não dependendo do tempo e do lugar em que possa ser interpretada e aplicada a norma. Nós, lendo a tese, sabemos que estamos a falar de um regime, e como bem diz «em vigor», e no atual Estado constitucional democrático, mas pensamos que devia ter sido mais específica no tempo e no espaço, uma vez que o DL 406/74, de 29 de agosto, é, como nos diz, um diploma de natureza compromissória. Ou podia ter feito um melhor questionamento tendo em conta a evolução societária, em especial tecnológica, e um melhor aprimoramento das forças e serviços de segurança desde 1974 até aos nossos dias.

Mantendo-nos nesta questão e na linha das suas conclusões e perguntas que retoma, gostaríamos que nos explicasse se mantém a posição: de ser necessário um regime com 
uma positivação da responsabilização dos promotores, dos danificadores etc., como acontece em Espanha.

É que na p. 94, diz-nos que o «Direito português tipifica penalmente a violação de alguns termos impostos ao direito de manifestação, que importam sanções quer para os participantes, quer para os promotores da manifestação. Nestes, incluem-se os indivíduos que causem danos a terceiros em consequência de atos de violência no decorrer de uma manifestação, os quais, além da responsabilidade civil, incorrem em responsabilidade criminal. De igual forma, os promotores podem ser responsabilizados, nos termos dos artigos $483 .^{\circ}$ e $490 .^{\circ}$ do Código Civil (Responsabilidade dos autores, instigadores e auxiliares), mesmo que não tenham praticado diretamente atos violentos, se estiverem preenchidos os pressupostos da responsabilidade civil». Ficamos sem saber se o Direito português - na sua unidade sistemática - garante o direito a e de se manifestar, e tutela os direitos e valores da comunidade. Sabemos que talvez quisesse fixar-se numa atualização (pp. 210 e 298), mas do quê?

Ou será que pretende proceder a uma extensão da responsabilidade penal dos atos praticados pelos manifestantes aos promotores, na linha da responsabilidade penal das pessoas coletivas (artigo 11. ${ }^{\circ}$, n. $^{\circ} 8$ e 9 do CP)? É que a responsabilidade civil solidária e subsidiária, como sabe, já pode ser assacada por força dos preceitos do código civil.

Os danos nos bens de terceiros pode enquadrar um facto subsumível a uma tipificação criminal, p. e p. pelos artigos $212 .^{\circ}, 213 .^{\circ}$ e $214 .^{\circ}$ do $\mathrm{CP}$, assim como a desobediência a ordem de dispersão de reunião pública, crime p. e p. pelo artigo 304. ${ }^{\circ}$, como nos diz na tese. Mas ficamos sem saber se aplica este preceito à desobediência de dispersão de manifestação ou se opta pelo crime de desobediência, p. e p. pelo artigo $348 .^{\circ}$ do $\mathrm{CP}$, ou se aplica a desobediência qualificada prevista no $\mathrm{Dl} \mathrm{n} .^{\circ}$ 406/74, regime jurídico dos direitos de reunião e manifestação.

Parece-nos que o olhar crítico que desenvolve entre as pp. 205 e 213, seguindo sempre de perto alguns autores, não está devidamente efetuado tendo em conta que olha para o regime de forma separada e compartimentada, quando no seu todo o regime já soluciona as questões que coloca. Impõe-se é um conhecimento do Direito e não apenas da norma ou de algumas normas.

Acresce que para as questões de criminalização de condutas que lesem ou coloquem em perigo de lesão bens jurídicos, devia convocar o princípio de reserva constitucional da restrição de direitos e liberdades fundamentais pessoais (artigo $18 .^{\circ}, \mathrm{n} .^{\circ} 2$ da CRP), que se impõe sempre que estamos na seara criminal. 
No que respeita à segunda questão de partida, consideramos que seria importante que nos explicasse dois pontos que não estão devidamente esclarecidos na tese de doutoramento:

(a) o primeiro é se podemos falar em «interferir» ou «ingerência» das forças de segurança, ou se o mais adequado juridicamente é falarmos em restrição de direito de manifestação na linha do texto constitucional. Veja que se lermos as pp. 131 a 138, em que nos apresenta o princípio constitucional da restrição de direitos fundamentais, parece-nos que nos quer centrar na restrição e não na interferência ou na ingerência, mas quendo lemos as conclusões voltamos a não entender o porquê de não se centrar na restrição, porque ingerência das forças de segurança pode significar ilegalidade e ilicitude da sua atuação;

(b) o segundo, é saber de que legitimidade nos está a falar quando se socorre do advérbio «legitimamente». Estamos a falar de uma legitimidade jus normativo-constitucional ou se nos está a falar de uma legitimidade sociológica ou se de ambas:

- se lermos as pp. 50, 133 e 136, parece-nos que se fixa no quadro constitucional, mas se lermos o terceiro $\S$ da p. 243, pensamos que resvala para uma legitimidade natural (quase sociológica) nessa limitação ao exercício do direito de manifestação - e se lermos a p. 214, verificamos que resvala para a legitimidade normativa.

Parece-nos que carece um pouco de explicação, uma vez que se socorreu de autores que trabalham estas questões como Reinhold Zippelius e Guedes Valente.

2. Outro ponto crítico da sua tese é não ter procedido a uma adequada teorização e sistematização dos espaços de manifestação: veja que nos fala de espaço aberto ao público, lugar privado de acesso ao público, de lugar público como se tudo fosse e não fosse a mesma «coisa», melhor, tivesse a mesma dimensão normativa. Veja como promove essa confusão em dois exemplos: (i) «espaço público ou de domínio público» (p. 14) e (ii) de «o direito de utilização dos lugares públicos e de domínio público» (p. 86). Segue a própria conflitualidade de 74 e a consequente imprecisão

Lamentamos que não tivesse aproveitado autores que trabalham estas matérias - Guedes Valente quando densifica os domínios público e privado da atuação do Estado na linha iniciada por Harmut Maurer e Marcello Caetano - de modo a que ficássemos cientes de que espaços está a falar. 
Hoje as forças de segurança deparam-se com duas dimensões de espaço que assenta em domínios: domínio público (designado por outros como espaço de domínio do Estado) e domínio privado ou não público (ou domínio de não Estado).

Os domínios públicos e privados subdividem-se em três categorias iguais: de acesso livre ou de acesso comum (Marcello Caetano), de acesso condicionado e de acesso restritivo. Gostaríamos que nos dissesse em que domínio se fixa a sua tese e em que categoria a sua posição final tem maior relevância.

3. A Senhora candidata, na p. 118, trata, citando Vieira de Andrade e José Alexandrino, de perspetivas e de formas de análise de direitos fundamentais. Não entrando na discussão dogmática de perspetivas e de formas, e fixando-nos nestes dois tópicos gostaríamos de saber em que perspetiva ou em que forma se pode afirmar o direito de manifestação.

4. A Mestre Ana Robalo, nas pp. 146-147, apresenta-nos uma tutela jurídica supranacional dos cidadãos - DUDH e CEDH -, mas ficamos sem saber se ao direito de manifestação é ou não garantida uma supranacionalidade jurídica; melhor, perguntamos se poder-se-á afirmar que os cidadãos, no plano do direito de manifestação, é um sujeito de direito supranacional e sujeito de uma jurisdição supranacional.

Por fim e antes de terminar, gostaria de saber se, quando trata do tema direito de manifestação face ao estado de sítio e ao estado de emergência - num campo de domínio diferenciado do que a Profa. Paula Veiga fala, mas quês e complementa -, o circunscreve ou não a um estado de exceção absoluto ou relativo ou se estamos perante um estado de exceção tácito. Quanto a este regime, consagrado no artigo $19 .^{\circ}$ da CRP - falta-lhe o estudo da tese de doutoramento de Jorge Bacelar Gouveia e dos textos de Giorgio Agamben.

5. Terminamos dizendo que gostamos de ler a sua tese, que levanta mais questões, mas o tempo não permitiria que ficássemos a debater página a página. Desejamos-lhe continuação de boas provas e responda apenas às questões materiais pela ordem que entender e melhor lhe aprouver. Reafirmamos que somos da opinião de que deve ser aprovada nestas provas de doutoramento, por ter apresentado um trabalho globalmente positivo.

Lisboa (UAL), 10 de julho de 2019 